\title{
Research on New Urbanization and Agricultural Modernization Coordinated Development in the Traditional Agricultural Areas
}

\author{
Yan peng ${ }^{1, a}$, Wenbin $\mathrm{Liu}^{2, b^{*}}$ and Chang $\operatorname{Tan}^{1, c}$ \\ ${ }^{1}$ School of Business Administration, Zhongnan University of Economics and Law, Wuhan, 430073, \\ China \\ ${ }^{2}$ Public Department, $\quad$ Wuhan Technology And Business University, Wuhan, 430065, China \\ b812926096@qq.com \\ * The Corresponding Author
}

Keywords: Traditional agricultural areas; New urbanization; Agricultural modernization; Coordinated development

\begin{abstract}
The traditional agricultural areas have weak and inefficient industries, poor liquidity of production factors, poor spatial agglomeration and slow urbanization. The establishment of a long-term mechanism of mutual promotion of new urbanization and agricultural modernization in traditional agricultural areas is the cornerstone of agricultural development and the key to enhancing rural development in China. Therefore, this paper attempts to explore the mechanism and path of the new urbanization and agricultural modernization coordinated development in the traditional agricultural areas from the view of industry-town integration, mutual promotion of workers and peasants, and urban-rural co-ordination. Based on the survey, we think, the traditional rural areas of new urbanization and agricultural modernization coordinated development should from the production integration of the city, mutual promotion between industry and agriculture, urban and rural common prosperity, based on agriculture, to the second, three industry multidimensional diffusion, according to the traditional agricultural resources and industrial base, selection of production city integration path according to local conditions, implementation of rural population from agriculture to non-agricultural, fulfilment of the nearby urbanization.
\end{abstract}

\section{Introduction}

New urbanization is our country's largest potential for domestic demand, and it is the only way to achieve modernization. It is of vital importance to promote the coordinated development of new urbanization and agricultural modernization. Realizing urbanization on the spot and taking the integration of the urban areas and narrowing the gap between urban and rural areas are not only the focus of adjusting the economic structure but also the key to release the development potential. However, the inertia of resource elements accelerated from rural to urban areas is still significant. As a key area for ensuring the national food security and ecological barrier, traditional agricultural areas have reason to become the pioneering areas and typical demonstration areas in our country to explore the coordinated development of new urbanization and agricultural modernization. Based on this, this study combines the universal problems in the process of new urbanization and agricultural modernization with the geographical features, individualized contradictions, from the perspective of industry-town integration, mutual promotion of workers and peasants, and urban-rural co-ordination, this paper explores the coordinated development mechanism and path of new urbanization and agricultural modernization in traditional agricultural areas.

\section{Based on the Coordinated Development Mechanism of Industrial Integration}

The Connotation of "City-industry Integration" Based on New Urbanization. China's new urbanization emphasizes people-oriented, with ecological, civilized and harmonious as the goal, pays attention to urban and rural areas overall planning, city-industry integration, and take the intensive development path. Therefore, in combination with the new urbanization background, "integration of industry and 
the city" is to adhere to the people-oriented principle and follow the essence of urban functions in urbanization, comprehensively consider the matching of industry, population and space to promote harmonious development of people, property and city, and give play to the leading role of the regional growth pole in the process of new urbanization.

The Internal Mechanism of "City-industry Integration". The core of City-industry Integration is people. According to their respective positions, all cities should give full play to the advantages of urban resources, improve supporting facilities and promote the industrial upgrading and development in the region. First of all, according to the location of the spatial structure of the region to determine the construction of industrial parks, to introduce industry and conduct follow scientific planning. Industrial development, will form a series of industrial chain, promote the development of regional economy.

Second, with the improvement of industrial parks, the improvement of transportation facilities and housing conditions around the area, the gradual concentration of population has not only increased industrial production efficiency, but also increased consumption and demand for services. It is necessary to introduce a variety of infrastructure, producer services and cultural life to create an environment conducive to livelihood, and to establish an accompanying urban function to meet people's growing needs.

Therefore, when a region imports industries and flows into the population, it will form an interactive relationship. In each stage, the development of different industries, people's needs are different, development, demand are regular, according to the various stages of scientific planning, the formation of a reasonable match, to achieve the rational use of resources to achieve maximum utility, In this way, "industry and city" can form a good cycle and promote each other's progress.

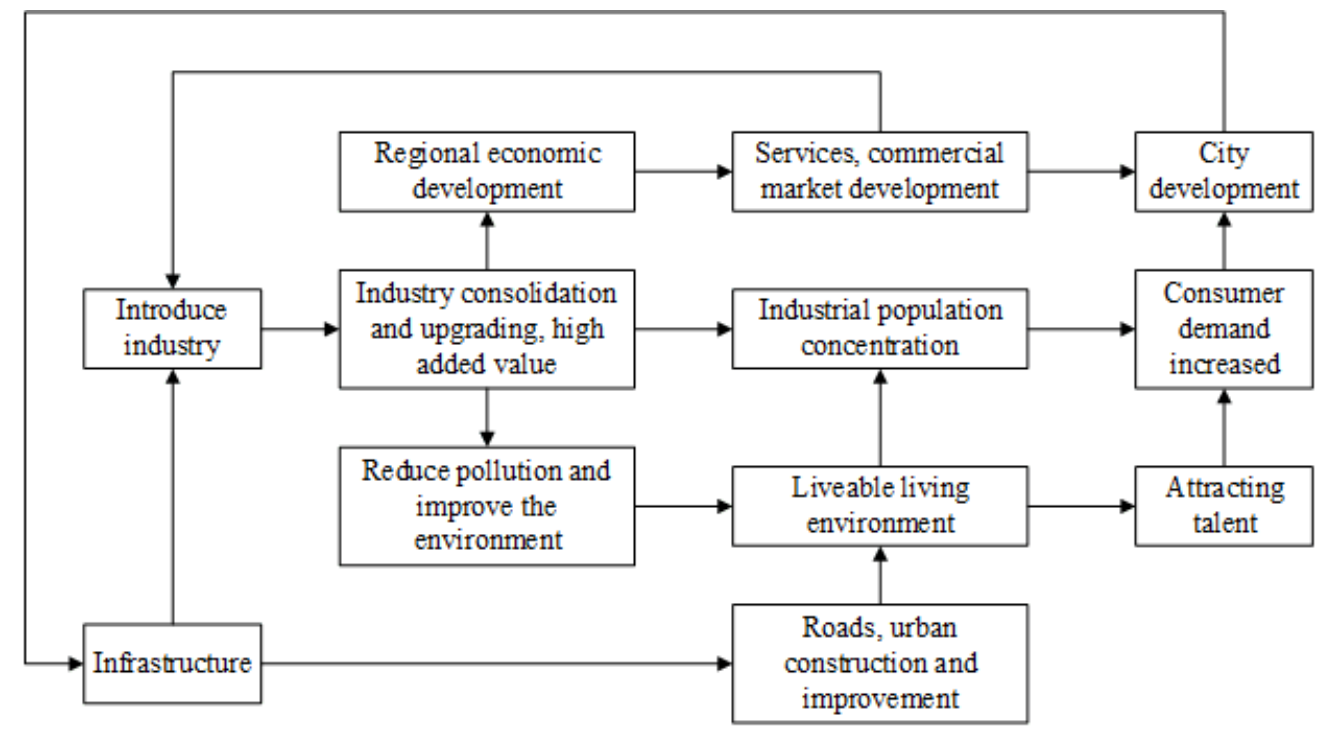

Figure 1. Internal mechanism flow chart of "City-industry Integration"

The Path of "City-industry Integration". First of all, locate the city. The construction of the new city should follow the essence of urban functions. For the integration of industry and cities in the whole country, it is necessary to comprehensively consider the industrial layout and urban planning of the whole country, to make a logical match with the scientific budget industries, population and space and to prevent the emergence of urban construction where people and industries are separated; The integration of cities and towns within the urban system should aim at the respective functions of large, medium and small cities. The division of labor in industries should be rationalized so as to prevent inappropriate matching of urban functions and industries, and to promote the coordinated development among central cities, sub-center cities and general cities; In the metropolitan area within a single city of mutual integration of the metropolis in the new city, satellite city, to form a benign interaction between industry and the city, the general urban construction of the new city, new area, through the city's functional orientation and industrial transfer, science to determine the 
new city, the new district can support the employment of how many people industry in a certain scale upgrade and expansion. To prevent the emergence of only a gathering place for migrant workers, or a situation that is difficult to achieve further after they are saturated.

Second, to plan the development of industries and promote regional economic development. All regions should analyze their own resources of special advantages and take advantage of their resources to develop industries accordingly. Starting from the carrying capacity of cities and towns, each region should give full scope to its own advantageous industries and promote the establishment of industrial parks and new districts so as to promote the growth of regional economy.

Thirdly, population, industry and city should promote each other's development. The City-industry Integration should pay attention to people-oriented development. People are the meeting point of industry and city development. "People" is not only an essential factor for industrial development, but also has certain needs for urban functions. Therefore, in order to achieve sustainable development, all three must be closely linked. "People" is the most flexible resource, its demand is also different from the general resource elements, the level of human needs is a simple to complex change. Industrial development not only transfers rural population, but also urban population. Their needs are different. Industrial parks can bring about the ruralization of the rural population and create non-agricultural income for them. They not only make their incomes more stable, are no longer subject to the cyclical agricultural production, but also greatly increase their incomes. The development of the industry will inevitably bring about the construction of supporting infrastructure such as infrastructure and real estate around the industrial zone, which will attract them to rent houses and buy houses in the area. "People" as the necessary supply of industrial development, at the same time, the city provides the relevant consumption, services to meet their needs. In this way, to achieve mutual promotion of people, industry and urban development.

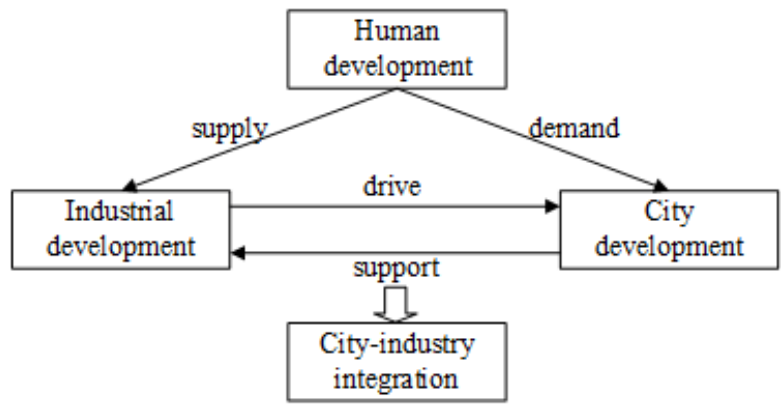

Figure 2. The relationship among people industry city

Fourth, improve the supporting functions of industry and urban development. Industrial development to promote the growth of industrial parks, industrial parks gather a large number of people, breeding a large number of needs, the need for relevant urban functionality to meet. Therefore, it is necessary to establish some public auxiliary facilities such as real estate, shopping mall and plaza so that the city can provide public service for the industry.

\section{Based on the Coordinated Development Mechanism between Industry and Agriculture}

The Relationship between Industrial Development and Agricultural Development. With the development of history, industry and agriculture generally go through the following stages: traditional agricultural economy dominates, traditional agriculture and modern industry coexist, modern industry dominates, and modern agriculture and modern industry coexist.

In the process of development of industry and agriculture, we can see that industrialization not only enjoyed the fruits of agricultural development, but also promoted the development of agriculture to a certain extent. Because of the basic role of agriculture, agriculture provides the basic elements to the industry. The primitive accumulation is inevitable. As the industrial development reaches a certain stage, some technical and equipment conditions created by its 
development provide support for agricultural development, which not only brings about agricultural productivity Increase, but also makes the agricultural structure has a certain degree of change. Therefore, industrial and agricultural development are mutually supportive and complementary.

\begin{tabular}{|c|c|c|c|c|}
\hline Induntria1 & Raw materials & & Technology, capital & 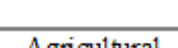 \\
\hline $\begin{array}{l}\text { Industrial } \\
\text { development }\end{array}$ & & Elements flow & & $\begin{array}{l}\text { Agncturural } \\
\text { Development }\end{array}$ \\
\hline
\end{tabular}

Figure 3. The relationship between industrial development and agricultural development

The Relationship among Industry, Agriculture, Farmers, Citizens. First of all, the relationship between industry and agriculture is manifested in that agriculture is the basic guarantee of industry and industry promotes efficiency of agriculture. Industry provides advanced agricultural equipment, technologies, fertilizers, pesticides, electricity and other agricultural means of production for agriculture. It also provides new ideas and new management methods for agricultural production, and changes agricultural traditional farming methods so as to industrialize agriculture and improve agricultural land output efficiency and agricultural production efficiency, to produce richer, more in line with modern needs of agricultural products.

Second, the relationship between industry and peasants is manifested in that industry can increase peasants' income and peasants can create value. Because agricultural activities are cyclical and agriculture is a low-return industry, farmers have limited income. Industrial development can attract peasants to work so that peasants no longer engage in agricultural activities and raise and stabilize their incomes. At the same time, peasants are the most basic human resources, creating a large amount of industrial output and boosting the returns of leading enterprises in industrial parks.

Thirdly, the relationship between agriculture and the public is as follows: Agriculture not only provides citizens with basic food and clothing but also provides a green environment. People are more willing to enjoy the green environment and fresh air provided by agriculture. Citizens have provided a vast market for demand for various products created by agricultural development.

Forth, the relationship between urban and rural residents: China is a big agricultural country, rural population accounts for a large proportion. However, the dualistic structure has long made the difference between the urban and rural population of our country in terms of quality of life, lifestyle and social welfare. This restricts the sustained and healthy development of agriculture and peasants. With the readjustment of our country's strategic planning, while promoting economic development, we must coordinate the basic relations between peasants and citizens and enhance their sense of happiness. This will not only help adjust the economic structure but also bring vitality to economic growth.

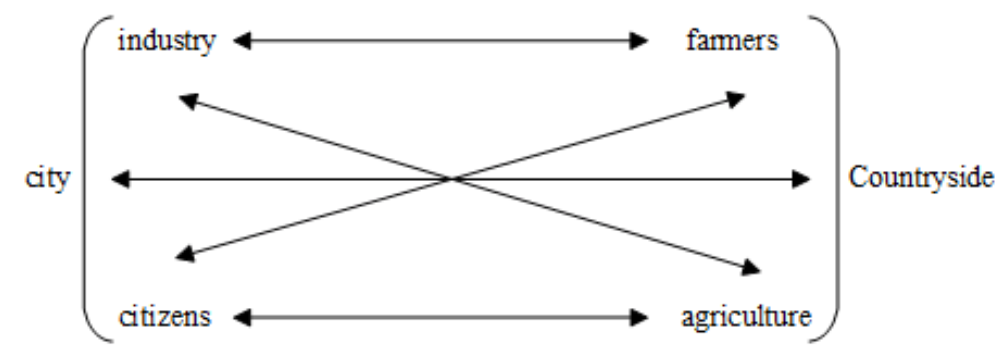

Figure 4. The Relationship among Industry, Agriculture, Farmers, Citizens

The Impact of Industrial Agriculture on Mutual Promotion. With the advancing integration strategy of urban and rural areas, the basic status of agriculture has been significantly strengthened and the long-acting mechanism for workers and peasants has been effectively established. This has led to the improvement of agricultural production efficiency, the continuous increase of agricultural output and the realization of agricultural production targets.

In some places, by vigorously fostering the leading enterprises of agricultural industrialization, invigorating peasants 'operating assets, driving peasants into the market, developing professional cultivation and breeding and broadening the channels for peasants to increase their incomes, the 
peasants' income has been broadened from a single land revenue to wages and assets and other aspects of income, so that farmers effectively achieve the goal of increasing income and wealth.

With the promotion of industry and agriculture, the level of economic and social development in rural areas is gradually increasing. In some places, the establishment of health villages and civilized villages is also being strengthened. The rural environment has obviously improved and the peasants' living style has also been increasingly transformed.

\section{Based on the Harmonious Development of Urban and Rural Development Mechanism}

The Connotation and Main Forms of Urban and Rural Integration. Urban-rural integration mainly consists of three aspects. First of all, urban-rural economic integration. For a long time, the policy of partial development of cities and industries in our country, the irrational flow of various resource elements and the unfair trade make the development of urban and rural economy lag behind. For example, urban and rural residents have different incomes, living expenses and various investment fields. With the industrialization of our country reaching a certain stage, the development of the rural areas will become shackles affecting the overall development of our country. Therefore, narrowing the economic gap between urban and rural areas will contribute to the social harmony and the overall development of the people.

Second, urban and rural space gathering. Traditional rural spatial aggregation is based on the traditional agricultural development mode, with the development of cities and rural areas, the spatial agglomeration will become more and more closely. The development of urbanization and agricultural modernization has changed the industrial structure of agriculture, accelerated the transfer of rural labors to non-agricultural areas and cities and towns, affected the peasants' production and life style, expanded their scope of social interaction, and social relations were no longer bound by the region. The public facilities in rural areas are also increasingly improved, the distance between rural areas and urban areas is shortened, and the accessibility of urban and rural areas is strengthened. In addition, in pushing the industrialization development, some rural areas are occupied, some rural areas with better geographies and strong infrastructure are supported by the industrial economy, and urbanization and urbanization have gradually developed.

Third, make overall plans for urban and rural public services. For a long time, due to the dual economic structure of urban and rural areas, the proportion of basic public services in China's fiscal expenditure is small, and the resources like funds, facilities, medical care, manpower and other resources are more in the cities, affecting rural infrastructure, social security, cultural education and household registration system. Farmers are not satisfied with their public needs, restricting the transformation and upgrading of agricultural production, slowing down the pace of agricultural development, limiting the improvement of farmers' quality of life, and aggravating the contradictions between urban and rural areas. Moreover, with the development of urbanization and industrialization in our country, the transfer of rural population has been brought about. However, the population transferred to cities and towns and the urban population originally treated in the past are treated differently in the aspects of basic public services and social security, which restrict the farmers' real development.

An Analysis of the Dynamic Mechanism of the Integration of "City" and "Countryside". The driving force of urban integration is the driving force of the city and the driving force of the countryside. The driving force of the city is generated by the development of urban industry, which plays a driving role in the development of rural areas. The driving force of rural areas is the industrialization of rural areas, and the development of industrialization drives rural areas closer to cities.

The integration of urban and rural development depends on internal motivation and external motivation. First of all, internal motivation is at the heart of rural urbanization and urban modernization, that is, from rural areas to urban areas. Industrial development brings population and resources together, and at the same time, it promotes the development of traditional agriculture to modern agriculture and stimulates rural development potential, attracting Investment, entrepreneurship from all quarters drives the rural economy. The various infrastructure construction 
and public services in rural areas have also gradually been completed and the countryside has been transformed. Urban modernization is the direction of urban development. According to its own function, location, and reasonable development of the cities in our country, we can not blindly develop into a metropolis. When the urban development reaches a certain degree of saturation, the population will be concentrated in a large amount, and the form of urban transportation will become more and more serious. Therefore, the development of cities should take into account the matching relationship between the population acceptance and the industry support. In the meantime, the development of the city will be properly extended, which will lead to the development of the surrounding countryside.

Second, external impetus is the implementation of various policies and measures. Such as financial policy, capital is the driving force for development, finance is its propellant. In promoting the urban and rural development, we must have the capital to invest and solve the financing problem in time. All these require the support of good financial policies. We should implement different financial measures according to the urban and rural development in different regions, encourage financial innovation, develop direct financing and establish a sound financial service system. Such as tax policies and some tax incentives for some enterprises investing in urban development in rural areas. This not only attracts all parties to invest in the rural areas, but also promotes the development of urban areas and rural areas and also promotes the diversification of rural industries. Needs to be combined with internal and external forces to better promote the development of urban and rural areas.

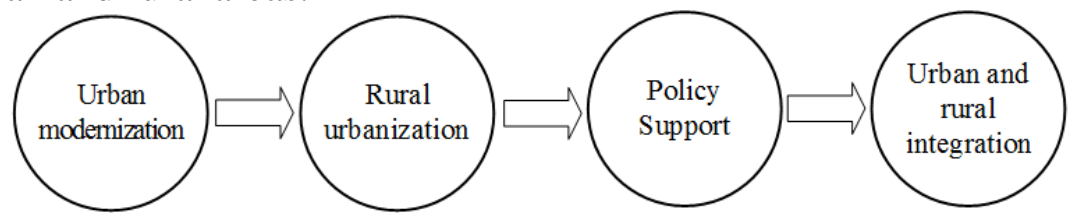

Figure 5. The driving force for the integration of urban and rural

The Goal of Urban-Rural Integration. The integration of urban and rural areas is an important train of thought for promoting development in our country. It does not mean that urban development and rural development are homogeneous. It narrows the gap between the two in all aspects by acknowledging the gap between urban and rural areas. In terms of employment, in addition to farm work, peasants have increased the proportion of urban employment in their immediate vicinity, increased their income channels and improved their peasant's traditional means of earning a living. In space gathering, the cities and villages are no longer divided states, the elements are more free to flow, the urban-rural exchanges are increasingly facilitated, and the level of urbanization in rural areas and peasants is raised. In the social life, urban and rural residents gradually become equal in enjoying public services, and are increasingly converging in culture and entertainment.

Economic growth is the guarantee of employment. With the development of urbanization, the employment structure in urban and rural areas has obviously improved. This shows that our urban and rural integration strategy has played a certain role in improving the urban-rural structure.

The integration of urban and rural areas improved the spatial pattern of urban and rural areas. It shifted the agricultural surplus labor force, promoted the agricultural scale operation, improved the labor survival rate, and gradually realized the agricultural modernization. At the same time, the urban modernized life style gradually extended to rural areas and improved the peasants' Living standards, thus increasing the overall urbanization level of the country.

The effect of urban-rural integration is also reflected in the cultural life. Culture is an important goal of the connotative development and a symbol of the people's quality of life and the degree of social civilization. Under the co-ordination of urban and rural development, the urban and rural public cultural service system and the development mechanism of cultural industries are promoted, cultural exchanges between urban and rural areas are promoted, the construction of new rural areas is promoted, and the rural heritage is fundamentally developed. 


\section{Acknowledgements}

Zhongnan University of Economics and Law Graduate Education Innovation Project (No. 2017B1009).

\section{References}

[1] L. X. Yang, Z. M. Jiang. Inquiry into Economic Issues, (2013)No. 10. p. 35. (In Chinese).

[2] Y. Y. Jiang. The Study on the City-Industry Integration in the process of Synchronization of "Four Modernizations"(Ph. D. , Shanxi University of Finance \& Economics, China 2016), p. 24.

[3] G. H. Li. The Study of the Development Path of the Intergration of Industries and Cities in China(Ph. D. , Anhui University, China 2014), p. 32.

[4] S. G. Luo. Journal of Shanghai Jiaotong university(Philosophy and Social Sciences), (2014) No. 4. p. 18. (In Chinese).

[5] C. Y. Xie, H. H. Hu. Journal of Finance and Economics, (2016)No. 1. p. 74. (In Chinese).

[6] W. Y. Zou, Y. Huang. Planners, (2014)No. 6. p. 34. (In Chinese).

[7] Information on http://www. aisixiang. com/data/106548. html.

[8] J. Y. Zhou, Y. X. Bai. Chinese Rural Economy, (2014)No. 6. p. 20. (In Chinese).

[9] L. J. LuoY. Z. ,Luo. Management world, (2014)No. 11. p. 73. (In Chinese).

[10] J. Yang. Finance \& Economics, (2017)No. 4. p. 70. 